\title{
MORINGA OLEIFERA LAM: UM ADSORVENTE NATURAL UTILIZADO NA REMOÇÃO DE CONTAMINANTES EM EFLUENTES LÍQUIDOS
}

\author{
G. F. EVANGELISTA ${ }^{1}$, I. M. SANTOS SOARES ${ }^{2}$ e L. H. Q. dos REIS ${ }^{2}$ \\ ${ }^{1}$ FEMC, Departamento de Engenharia Química \\ ${ }^{2}$ FACIT, Faculdade de Engenharia Química \\ E-mail para contato: gabriela.evan@yahoo.com.br
}

\begin{abstract}
RESUMO: O presente trabalho tem como objetivo realizar uma revisão bibliográfica referente à utilização da Moringa oleifera na clarificação e descontaminação da água. A Moringa é uma árvore que possui sua origem na Índia encontrada também no nordeste do continente africano. No Brasil, ela é comum no cerrado e no semi-árido e em outros países tropicais. Na região nordeste do Brasil, onde a moringa é mais facilmente encontrada, ela é usada para clarificar e descontaminar a água, fato que motivou o desenvolvimento de inúmeras pesquisas com o objetivo de incentivar o uso da moringa como uma alternativa no tratamento da água. Serão discutidas neste trabalho, as diferentes metodologias que utilizam a moringa como adsorvente natural no tratamento da água, bem como os resultados dessas pesquisas e comparação da Moringa oleifera com adsorventes sintéticos e minerais e o impacto dos mesmos no meioambiente.
\end{abstract}

\section{INTRODUÇÃO}

O aumento exponencial da população e as sensíveis alterações climáticas que ocorreram nos últimos anos tornaram o planeta incapaz de regenerar alguns recursos naturais em tempo hábil para suprir as necessidades de consumo da população, o que diminui a disponibilidade desses recursos, como a água. A escassez de água no planeta indica a necessidade da intervenção humana para tornar o processo de recuperação desse recurso mais eficiente para compensar o aumento populacional (Tomasoni, et al., 2009 apud Souza, 2014).

Uma das inúmeras consequências do consumo exagerado por parte da humanidade é o descarte inadequado de detritos, que leva à contaminação de um volume ainda maior de água que deverá ser tratada antes de seu posterior consumo. Existem vários tipos de resíduos que são nocivos à saúde do homem, entre eles podemos citar o grupo de compostos conhecidos como BTEX (benzeno, tolueno, etilbenzeno, e xileno) que possuem várias aplicações em diversos setores industriais (Almeida, 2010). Além desses compostos químicos, existem inúmeros micro-organismos que são prejudiciais aos seres humanos e que podem se desenvolver na água devido ao descarte indevido de resíduos ou a poluição inerente ao progresso da sociedade (Oliveira, 2010).

Para tornar a água potável, a literatura conta com diversas metodologias aplicadas em processos que progrediram paralelamente ao avanço tecnológico. Segundo Ghebremichael (2004), a coagulação se destaca como uma das partes mais importantes no tratamento de água, auxiliando na remoção de partículas suspensas e dissolvidas, caracterizando-se como uma das 
primeiras unidades desse processo. O processo de coagulação desestabiliza partículas coloides em suspensões estáveis, essas partículas desestabilizadas são floculadas para serem removidas por sedimentação ou filtração. Observou-se uma remoção de mais de $99 \%$ das bactérias e vírus com aplicação correta da metodologia referida (Faust e Aly, 1998 apud Ghebremichael, 2004). Embora esses procedimentos físico-químicos sejam eficientes no tratamento da água, eles se baseiam no uso de compostos químicos que se acumulam ao longo da cadeia alimentar e em longo prazo podem causar sérios danos à saúde humana, um exemplo desse fato seria o desenvolvimento de doenças neurológicas que podem ser causadas pela elevada concentração de alumínio no organismo (Freitas et al, 2001).

Em virtude dos impactos ambientais que podem ser causados pela utilização das técnicas de tratamento, a procura por meios naturais que substituam os métodos convencionais chama a atenção de estudiosos e pesquisadores da área. Nesse contexto, a Moringa oleifera surge como uma escolha alternativa de floculante/coagulante natural, pois apresenta um conjunto de características favoráveis ao tratamento de água (Almeida, 2010).

A Moringa oleifera é um espécime da família Moringaceae, originária da Índia e comum no nordeste do continente africano. É uma árvore de médio porte que pode atingir cerca de 10 metros de altura. Possui diversas aplicações em muitos países, nas indústrias farmacêuticas, alimentícias e cosméticas (Almeida, 2010). No continente africano existem vários relatos da utilização da moringa no combate à desnutrição devido à sua alta concentração de nutrientes (Bellostas et al, 2010).

\section{DESENVOLVIMENTO}

O presente trabalho pretende realizar uma comparação entre algumas publicações que avaliaram o uso da moringa como adsorvente natural para remoção tanto de microorganismos quanto a remoção de alguns metais, como o alumínio.

A seção 2.1 mostra brevemente as principais características da Moringa oleifera Lam, apresentando imagens da árvore, vagem e sementes do espécime.

A seção 2.2 relaciona as aplicações da moringa para tratamento da água em diferentes trabalhos que tem objetivos diversos e metodologias distintas.

A seção 2.3 sumariza todos os conceitos vistos nas seções anteriores e discorre sobre os resultados obtidos pelos autores dos trabalhos citados.

\subsection{Características da Moringa oleifera Lam}

Como citado anteriormente, a Moringa oleifera, também conhecida na Índia como Sajina e Shekta, nos Estados Unidos como horseradish tree e no Brasil como "quiabo-dequina" e lírio branco, é uma das 14 espécimes da família Moringaceae, como a Moringa Stenopetala (Bellostas et al, 2010).

Segundo Almeida (2010), as árvores de moringa podem ser cultivadas a partir de suas sementes, mudas ou estacas, suportando longos períodos de seca, o que as tornam aptas a 
sobreviver no clima semi-árido. A Figura 1 mostra a vagem madura da Moringa pronta para extração da semente.

Figura 1 - Vagens da Moringa

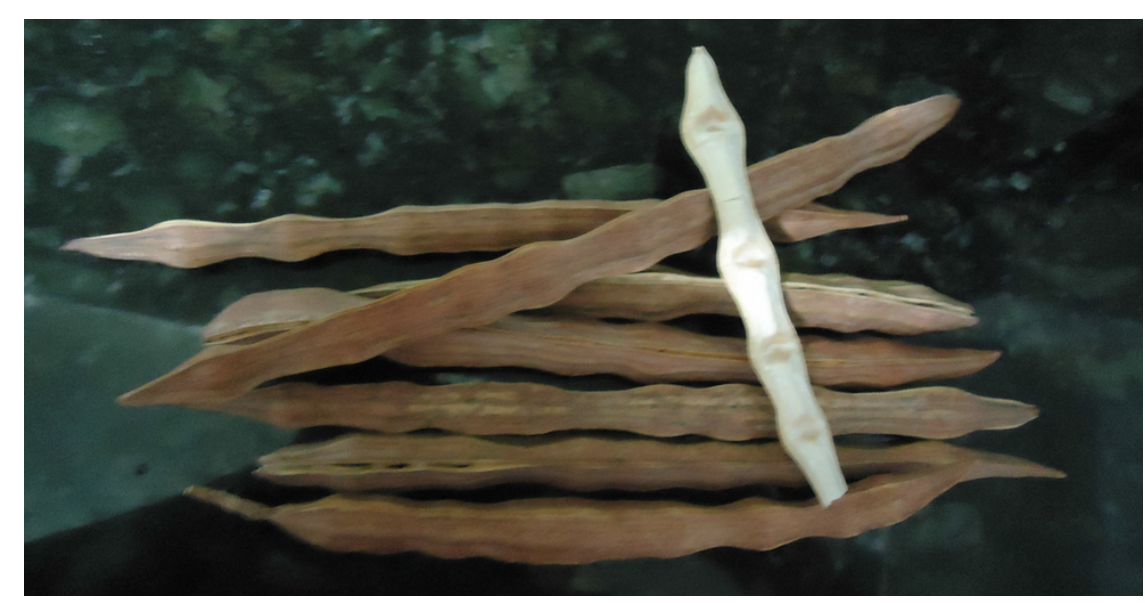

A moringa é fonte de vários nutrientes, sendo considerada por muitos estudiosos uma árvore milagrosa ("The Miracle Tree"), devido a sua elevada concentração de nutrientes como $\beta$-caroteno, ferro, cálcio, potássio, vitamina $\mathrm{C}$ e vitamina A. A Figura 2 exemplifica a distribuição desses nutrientes nas folhas da moringa em comparação com a ingestão de 1,0 gramas dos respectivos alimentos (Pezzarossi, 2004 apud Almeida, 2010).

\section{Figura 2 - Comparação nutritiva das folhas de Moringa oleifera}

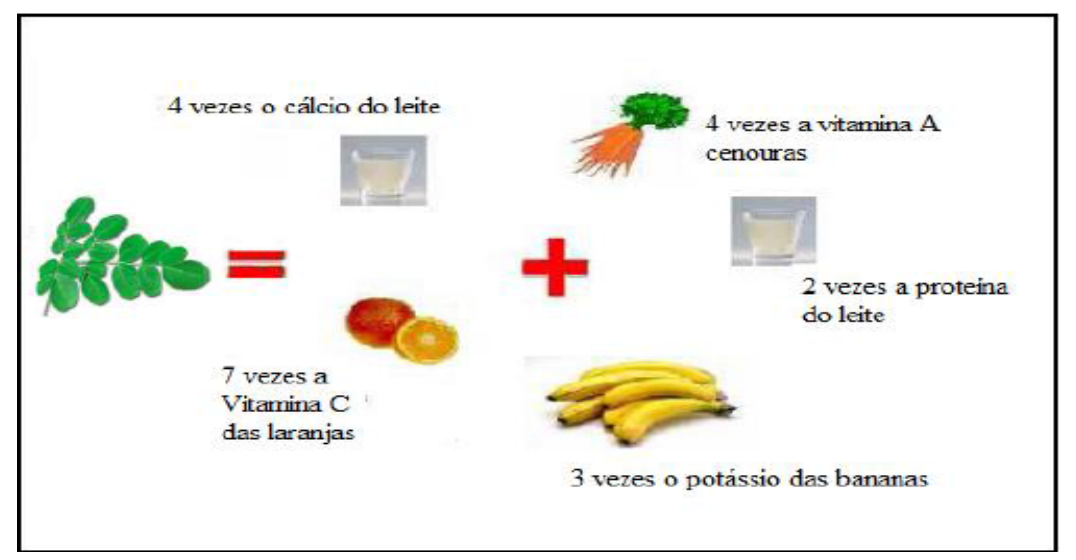

\subsection{Principais Aplicações da Moringa}

A moringa possui diversas aplicações em vários setores industriais, mas a principal aplicação à área de Engenharia Química é a sua utilização como adsorvente natural no tratamento da água. A moringa apresenta resultados significativos na clarificação de águas com alta turbidez, na remoção de micro-organismos e metais pesados de efluentes. Ela pode ser utilizada in natura, como uma torta feita das sementes para realizar a floculação/coagulação (Almeida, 2010), ou pode ser modificada por ativação superficial através de pirólise ou tratada com hidróxido de sódio (Bansal et al, 1988 apud Dada et al, 2012). 
O processo de adsorção consiste na diferença entre as forças moleculares insaturadas e desestabilizadas presentes nas superfícies sólidas. Quando uma superfície sólida entra em contato com um fluido, ocorre uma interação entre os campos de forças superficiais sólidofluido. A superfície do sólido atrai e retém as moléculas, átomos e íons do fluido, resultando em uma maior concentração destes nas proximidades da superfície sólida (Bansal et al, 1988 apud Dada et al, 2012). Na Figura 3 é possível observar uma das estruturas químicas presentes na superfície de alguns carvões ativados.

Figura 3 - Grupos Químicos Na Superfície De Carvões Ativados

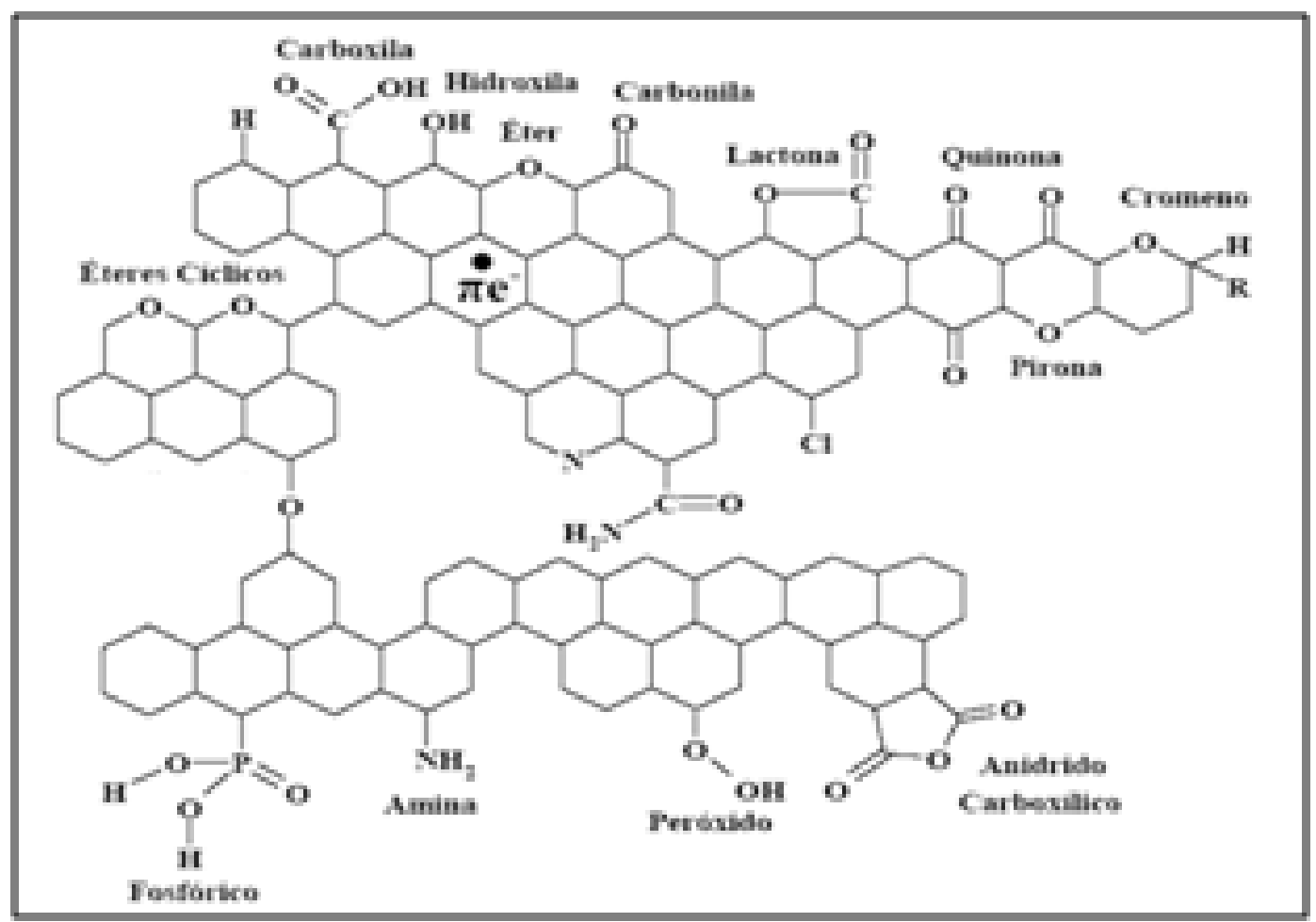

Uma das atribuições da moringa descritas por Oliveira (2010) é o uso da árvore no tratamento de lixiviado, um líquido de cor cinza-escuro de odor desagradável formado pelo depósito irregular e consequente reação química.

Além do tratamento de lixiviado, a moringa pode ser utilizada no processo de fitorremediação, técnica que consiste na utilização de plantas como agente de descontaminação, para conter ou tornar inofensivos determinados contaminantes ambientais em determinada área, a sua vantagem consiste em ser economicamente viável e apresentar potencial para tratamento in situ, ou seja, pode ser tratado no local da contaminação (Oliveira, 2010).

\subsection{Discussão}

Dentre a revisão bibliográfica feita é possível perceber que a maior parte das pesquisas desenvolvidas disponíveis sobre a aplicação da Moringa oleifera são de pesquisadores de 
países como a Índia e países do continente africano, onde a espécie é encontrada com maior facilidade. Essas pesquisas têm um foco na análise dos valores nutricionais, compostos que suas folhas possuem (Bellostas et al, 2010), suas características antibióticas, anticancerígenas (Fahey, 2005), para assim poder combater a desnutrição e mortalidade.

A tese de Almeida (2010) compara a utilização da torta feita à base de semente da moringa com o carvão ativado comercial, os resultados obtidos retratam a comparação da adsorção do conjunto BTEX e remoção desses compostos de efluentes. Segundo Almeida (2010), a torta de moringa é eficiente como material adsorvente para compostos orgânicos como BTEX, observando-se uma adsorção diretamente proporcional ao aumento do $\mathrm{pH}$ da amostra até este se igualar a 7,0, a partir deste ponto a adsorção passa a ser inversamente proporcional ao $\mathrm{pH}$.

A referida autora obteve a partir da análise de amostras com $\mathrm{pH}$ igual 7,0 para benzeno, tolueno, etilbenzeno, $p$-xileno e $o$-xileno as respectivas porcentagens de adsorção $74,92 \%$, $85,18 \%, 86,53 \%, 88,05 \%, 87,30 \%$. Ela observou também que a Moringa oleifera apresenta sítios com diferentes energias adsortivas. A autora sugeriu, a partir dos dados, que pode existir uma relação entre as interações hidrofóbicas do BTEX e a superfície da torta de Moringa oleifera. A torta de moringa se mostrou menos eficiente na adsorção de BTEX em relação ao carvão ativo comercial, porém as diferenças foram relativamente pequenas, visto que a torta não passou por um pré-tratamento, o que a caracteriza como uma solução eficiente e de baixo custo para ser usada na adsorção de BTEX em matriz aquosa.

Para Ghebremichael (2006) a Moringa oleifera se mostrou semelhante ao sulfato de alumínio no processo de coagulação e condicionamento de lodo. Assim, ele sugere que a moringa pode ser usada como coagulante e desinfetante em sistemas de tratamento de água.

De acordo com o trabalho de Ghebremichael (2006), foi possível isolar a proteína responsável pelo caráter coagulante da Moringa oleifera, denominado em sua dissertação como MOCP ("Moringa Oleifera Coagulante Protein") e foi identificada como uma proteína de baixa massa molecular com um ponto isoelétrico elevado. De acordo com os resultados de Ghebremichael (2006), a semente de moringa contém uma população heterogênea de proteínas coagulantes devido à existência de duas ou mais sequências de aminoácidos.

\section{CONCLUSÕES}

De acordo com a bibliografia revisada, é possível observar que os estudos sobre a potencialidade da moringa como adsorvente natural foi comprovada em escala laboratorial, e suas propriedades físico-químicas foram amplamente estudadas por diversos pesquisadores (Santana et al, 2010). A partir dos resultados apresentados é possível concluir que a moringa é uma árvore que possui diversas aplicações e que deveria ser estudada com mais profundidade.

Para futuros projetos espera-se que os estudos que foram desenvolvidos sejam aplicados em grande escala, se possível. Considerando o fato de que a maioria dos autores confirmou a viabilidade econômica na substituição de determinados agentes coagulantes sintéticos pela moringa.

\section{REFERÊNCIAS}


ALMEIDA, I. L. S. A avaliação da capacidade de adsorção da torta de Moringa Oleifera para BTEX em amostras aquosas. Dissertação (Mestrado em Química) - Instituto de Química, Universidade Federal de Uberlândia, Uberlândia, 2009. Disponível em: $<$ http://repositorio.ufu.br/handle/123456789/806>. Acesso em: 17 de set. 2014.

BANSAL, R. C.; GOYAL, M. Activated carbon adsorption. Nova Iorque: Editora Taylor \& Francis Group, 2005.

BELLOSTAS, N.; SØRENSEN, J. C.; NIKIEMA, A.; SØRENSEN, H.; PASTENARK, D.; KUMAR, S. Glucosinolates in leaves of Moringa species grown and disseminated in Niger. African Journal of Agricultural Research Vol. 5(11), 2010. Disponível em: $<$ http://www.academicjournals.org/AJAR>. Acesso em: 20 jan. 2015.

FAHEY, J.W. (2005). Moringa oleifera: A review of the medical evidence for its nutritional, Therapeutic, and prophylactic properties. Part 1. Trees for Life J. Disponível em: $<$ http://www.TFLJournal.org > . Acesso em: 15 jan. 2015.

FREITAS, M. B.; BRILHANTE, O. M.; ALMEIDA,L. M. Importância da análise de água para a saúde pública em duas regiões do Estado do Rio de Janeiro: enfoque para coliformes fecais, nitrato e alumínio. Cad. Saúde Pública, Rio de Janeiro, v. 17, 2001. Disponível em: $<$ http://www.scielo.br/scielo.php?script=sci_arttext\&pid=S0102311X2001000300019\&lng=en\&nrm=iso>. Acesso em: 6 mar. 2015.

GHEBREMICHAEL, K. A. Moringa seed and pumice as alternative natural materials for drinking water treatment. KTH Land and Water Resources Engineering, Asmara: 2004. Disponível em: < http://www.ircwash.org/sites/default/files/Ghebremichael-2004Moringa.pdf $>$. Acesso em: 12 jan. 2015.

OLIVEIRA, Z. L de. Avaliação do uso da Moringa oleifera Lam para fitorremediação e tratamento de lixiviados de aterros sanitários. Dissertação (Mestrado) - Universidade Federal de Pernambuco. CTG. Programa de Pós-Graduação em Engenharia Civil, Recife: O Autor, 2010.

SANTANA, C. R.; PEREIRA, D. F.; ARAÚJO, N. A.; CAVALCANTI, E. B.; SILVA, G. F. da. Caracterização Físico-Química Da Moringa (Moringa oleifera Lam). Revista Brasileira de Produtos Agroindustriais, Campina Grande, v. 12. n. 1, 2010.

SOUZA, J. R. A Importância da Qualidade da água e seus Múltiplos Usos. Caso Rio Almada, Sul da Bahia, Brasil. REDE - Revista Eletrônica do Prodema, Fortaleza, v. 08, n. 1, 2014. Disponível em: <http://www.periodicos.ufc.br/index.php/rede>. Acesso em: 06 mar. 2015. 